Research Paper

\title{
NAIDPH Oxidase: a Target for the Modulation of the Excessive Oxidase Damage Induced by 0vertraining in Rat Neutrophils
}

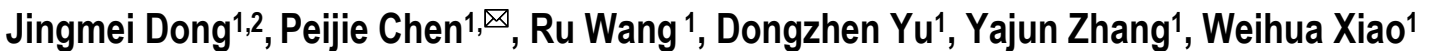

1. Department of Sports Science, Shanghai University of Sport, Shanghai 200438, China

2. Institute of Physical Education, Lanzhou City University, Lanzhou 730070, China

$\triangle$ Corresponding author: Peijie Chen, Department of Sports Science, Shanghai University of Sport, Shanghai 200438, China. Tel: +86-21-51253016; Fax: +86-21-51253626; E-mail: chenpeijie@sus.edu.cn; chenpeijie1961@hotmail.com

() Ivyspring International Publisher. This is an open-access article distributed under the terms of the Creative Commons License (http://creativecommons.org/ licenses/by-nc-nd/3.0/). Reproduction is permitted for personal, noncommercial use, provided that the article is in whole, unmodified, and properly cited.

Received: 2011.02.18; Accepted: 2011.07.09; Published: 2011.07.19

\begin{abstract}
Objective: The purpose of this study is to demonstrate that NADPH oxidase mediating the ROS production is the major pathway for ROS generation in neutrophils during exercise. NADPH oxidase, as a target can modulate oxidative damage induced by overtraining, which can be value to the prevention of exercise-induced immunosuppression.

Methods: Thirty male Wistar rats were randomly divided into three groups: a negative control group $(\mathrm{C}, \mathrm{n}=10)$, an overtraining group $(\mathrm{E}, \mathrm{n}=10)$ and an overtraining + DPI intervention group $(D, n=10)$. Groups $E$ and $D$ were trained on a standard treadmill with progressive load for 11 weeks. After 36-40 h from the last training, eight rats were randomly selected from each group, and blood was sampled from the orbital vein. ELISAs were used to measure serum cytokine levels and lipid peroxidation in blood plasma. Flow cytometry with Annexin V / PI double staining was used to measure neutrophil apoptosis and necrosis. DNA damage in lymphocytes was tested using single cell gel electrophoresis (SCGE). The co-localization between gp91phox and p47phox of the NADPH-oxidase was detected using immunocytochemistry and confocal microscopy.

Results: 1) Compared with group C, the concentrations of IL-1 $\beta$, IL-8, and TNF- $\alpha$ were significantly increased and MCP-1, and CINC were significantly decreased in blood plasma from group $\mathrm{E}(\mathrm{P}<0.01$ and $\mathrm{P}<0.05$, respectively). Concentrations of IL- $1 \beta$ and MCP-1 were decreased ( $\mathrm{P}<0.05)$, and IL-8 and TNF-a were significantly increased ( $\mathrm{P}$ $<0.05$ ) in blood plasma from group D. MDA and MPO were elevated in plasma from groups $\mathrm{E}$ and $\mathrm{D}(\mathrm{P}<0.01$ and $\mathrm{P}<0.05$, respectively). 2) Compared with group $\mathrm{C}$, the percentage of neutrophils apoptosis were significantly elevated $(\mathrm{P}<0.01)$ in both groups $\mathrm{E}$ and $\mathrm{D}$, and the percentage of cell death was raised in group $\mathrm{E}(\mathrm{P}<0.05)$. No significant change was observed in group D. 3) Compared with group C, the number of comet cells, an indicator of DNA damage, was significantly increased $(\mathrm{P}<0.01)$, and the width and tail length of comet cells were notably increased in group E, while no significant increase was observed in group D. 4) The p47phox protein translocated to the cell membrane and co-localized with the gp91 phox subunit of NADPH oxidase in neutrophils activated by overtraining.

Conclusion: 1) Excessive exercise led to an increased secretion of inflammatory cytokines and chemokines in peripheral blood, and it may have induced tissue inflammation 2) Overtraining can activate the NADPH oxidase-mediated overproduction of ROS, leading to increased lipid peroxidation. 3) NADPHoxidase in neutrophils as a target, was responsible for ROS, oxidative damage to phagocytes and lymphocytes and changes to inflammatory cytokines and immune regulatory factors all affect cellular immune functions and may be causative factors for exercise-induced immunosuppression.
\end{abstract}


Key words: overtraining; NADPHoxidase; neutrophils; radical oxygen species (ROS); lymphocytes; Cytokine; DNA damage; intervention.

\section{Introduction}

A variety of studies have demonstrated that exercise induces considerable physiological change in the immune system. Nieman [1] (1989) and Pedersen [2] (1994) provided suggestive evidence that the increased incidence of upper respiratory tract infections (URTI) was associated with athletes after marathon running. The relationship between the amount of exercise and URTI incidence has been described using the "open window theory" and "J-shaped curve" theory, leading to the proposal that exercise-induced immunosuppression (EIS) was responsible. Lancaster (2004) [3] examined type 1(Th1) and type 2 (Th2) T helper cells and their secreted cytokines, discovering that prolonged strenuous exercise resulted in an imbalance between Th1 and Th2 responses and a shift from Th1 to Th2. This imbalance resulted in attenuated cellular immunity and strengthened humoral immunity. The key to solving the problem of EIS will be to understand why overtraining weakens cellular immune function. During an immune response, $\mathrm{T}$ helper cell differentiation is regulated by interactions between the innate and adaptive immune systems. The innate immune system, consisting of phagocytes (such as macrophages and neutrophils), acts as the first line of defense for the body, can kills viruses and other microorganisms by producing reactive oxygen species (ROS) in a "respiratory burst" that is mediated by reduced form of nicotinamide-adenine dinucleotide phosphate (NADPH) oxidase [4]. It is well know that exercise could induced an augmented respiratory burst in phagocyte, In these processes, the series of cellular defense factors released include proteases and superoxide anions induced by exercise, which may causes the self-degradation of phagocytes and the release of cytokines. These cytokines then influence $\mathrm{T}$ cell differentiation and further activate the NADPH oxidase pathway to release more ROS that may induce lympholeukocyte injury and neutrophils apotosis. We hypothesize that the above mentioned processes may cause cellular oxidative damage and inhibit cellular immunity induced by overtraining.

In view of this hypothesis, we performed an assay based on single cell gel electrophoresis (SCGE), as described by Singh [5], with some modifications to measure DNA damage in lymphocytes after overtraining. DPI, an effective inhibitor of NADPH oxidase, was used to suppress NADPH oxidase activity and to reduce ROS production [6]. On the basis of the impact of prophase overtraining on leukocyte respir- atory burst and phagocyte function and the hypothesis that the production of excess ROS via NADPH oxidase was induced by overtraining, we measured levels of apoptosis and necrosis in neutrophils and calculated the survival ratio. The production of ROS in neutrophils was analyzed by flow cytometry, DNA damage and the production of inflammatory factors. In addition, DPI was used as an antioxidative agent to examine the mechanism behind lymphocyte DNA damage and to investigate oxidative damage as a potential therapeutic target for treating immunosuppression induced by overtraining.

\section{Materials and Methods}

\section{Reagents}

Reagents: Diphenylene iodonium (DPI), Dimethyl Sulfoxide (DMSO), DAPI staining solution, fetal calf serum and RPMI-1640 medium were purchased from Sigma-Aldrich (USA). Nitroblue tetrazolium (NBT) and trypan blue stain were purchased from GIBCO (USA). Polymorphprep ${ }^{\mathrm{TM}}$ and lymphocyte isolation solution were obtained from AXIS-SHIELD (Norway).

SCGE reagents: Sepharose with a normal melting point was obtained from Bio Basic Inc., and sepharose with a low melting point was obtained from AppliChem. The cell lysis buffer contained $2.5 \mathrm{~mol} / \mathrm{L} \mathrm{NaC1}$, $100 \mathrm{mmol} / \mathrm{L}$ EDTA, $10 \mathrm{mmol} / \mathrm{L}$ Tris, $1 \%$ sarcosine sodium ( $\mathrm{pH} 10), 1 \%$ Triton $\mathrm{X}-100$, and 10\% DMSO. Electrophoresis solution consisted of $300 \mathrm{mM} \mathrm{NaOH}$ and 1 mM EDTA ( $\mathrm{pH} 13)$. The balanced neutralization solution contained $0.4 \mathrm{~mol} / \mathrm{L}$ Tris- $\mathrm{HC} 1$ ( $\mathrm{pH} 7.5$ ).

Kits: ELISA kits for blood inflammatory factors were purchased from D\&G (Germany). Cell apoptosis kits were obtained from Beckman Coulter (USA). Monocellular electrophoresis kits were purchased from Kangjiang biological company in Shanghai. Kits for NADPH-xidase treatment were purchased from JieMei gene and medical technology company in Shanghai.

\section{Animal and overtraining protocol construction}

Thirty male Wistar rats (weight $225 \pm 6.7 \mathrm{~g}$ ) were purchased from BK biological technology company in Shanghai and were fed for a one week acclimatization phase (environmental temperature $20-25^{\circ} \mathrm{C}$ with a 12 $\mathrm{h}$ light/dark cycle and free access to standard pellets and drinking water). Ten rats were randomly chosen as the negative control group $(\mathrm{C}, \mathrm{n}=10)$, the remaining 
rats were subject to a 4 -week treadmill training regimen $(\mathrm{V}=22.5 \mathrm{~m} / \mathrm{min}$, one hour per session per day), and then these rats were divided into an overtraining group $(\mathrm{E}, \mathrm{n}=10)$ and an overtraining and DPI intervention group $(D, n=10)$. The progressive increase in training intensity and frequency were in accordance with the methods reported by Hohl (Table 1) [7].At the same time, the negative control group was handled and exposed to the treadmill to control for stress of treadmill environment. The experimental protocol was approved by the Ethics Review Committee for Animal Experimentation of Shanghai University of Sports. At the start of week 5 , rats in group D were injected intraperitoneally with DPI $\left(0.2 \mathrm{mg} \mathrm{kg}^{-1}\right)$ half an hour before training, as described previously [6]. The diluent solution ( $0.5 \%$ glucose) used for DPI injections was administered alone to the group $\mathrm{C}$ and group E.

During the eleven weeks of treadmill exercise, we monitored the dynamic change weight of rat. Blood samples were taken from the fossa orbitalis venous plexus and the serum hydrocortisone and virosterone levels were measured. A significantly lower of this index in the control exercise groups was considered an indication of success for the overtraining protocol referring to our previous experiment [8]. In addition, weak muscle contraction after stimulation and a sudden decrease in motor capacity were used as the criteria for exhaustion.

Table 1. The rat overtraining protocol

\begin{tabular}{llllll}
\hline $\begin{array}{l}\text { Experimental } \\
\text { week }\end{array}$ & $\begin{array}{l}\text { Training } \\
\text { phase }\end{array}$ & $\begin{array}{l}\text { Training } \\
\text { speed } \\
(\mathrm{m} \text { min }\end{array}$ & $\begin{array}{l}\text { Training } \\
\text { time } \\
(\mathrm{min})\end{array}$ & $\begin{array}{l}\text { Number } \\
\text { of daily } \\
\text { sessions }\end{array}$ & $\begin{array}{l}\text { Recovery } \\
\text { time } \\
\text { between } \\
\text { training } \\
\text { sessions } \\
\text { (h) }\end{array}$ \\
\hline 1 & & & & 24 & 24 \\
2 & AT1 & 15 & 20 & 1 & 24 \\
3 & AT1 & 20 & 30 & 1 & 24 \\
4 & AT1 & 22,5 & 45 & 1 & 24 \\
$5-8$ & AT1 & 25 & 60 & 1 & 24 \\
9 & AT2 & 25 & 60 & 1 & 24 \\
10 & T2x & 25 & 60 & 2 & 4 \\
11 & T3x & 25 & 60 & 3 & 3 \\
\hline
\end{tabular}

\section{Blood sampling and serum parameter measure- ment}

After eleven weeks on the overtraining protocol, in order to avoid the acute effect of exercise and other immune response of sacrificed, $3 \mathrm{ml}$ blood sample was taken from the fossa orbitalis venous plexus, $36-40 \mathrm{~h}$ after the last training. In all, $0.8 \mathrm{ml}$ blood was placed in an anticoagulation tube with heparin, centrifuged at 3,000 r/min for $5 \mathrm{~min}$ to isolate plasma, and frozen at $-18^{\circ} \mathrm{C}$ until use. Cytokine-induced neutrophil chemoattractant (CINC), interleukin-1 $\beta$ (IL-1ß), interleukin-8 (IL-8), monocyte chemoattractant protein 1 (MCP-1), tumor necrosis factor (TNF- $\mathrm{a})$, myeloperoxidase (MPO) and malonaldehyde (MDA) were measured using ELISA kits. Then, $2 \mathrm{ml}$ blood was added to an anticoagulation tube with heparin to isolate neutrophils, monocytes and lymphocytes. The remaining $0.2 \mathrm{ml}$ of blood was added to an EDTA anticoagulation tube and was immediately delivered to Second Military Medical University to be tested for common biological indicators.

\section{Separation of neutrophils, monocytes and lym- phocytes}

In accordance with the Polymorphprep ${ }^{\mathrm{TM}}$ instructions, $2 \mathrm{ml}$ of separation solution was added to a centrifuge tube, blood samples were spread carefully on the surface of the separation solution, and the tubes were centrifuged $\left(450 \mathrm{~g}, 35 \mathrm{~min}, 18-22^{\circ} \mathrm{C}\right)$. The separation layer containing neutrophils, monocytes and lymphocytes was isolated and washed twice using $0.45 \% \mathrm{NaCl}$ hypotonic solution and then PBS respectively Then, $0.4 \%$ trypan blue was added for counting, and the concentration of cells was adjusted to $1 \times 10^{7}$ cells $/ \mathrm{ml}$; the concentration of live cells was no less than $96 \%$. Finally, the cells were suspended in pre-chilled RPMI-1640 culture medium.

\section{NADPH oxidase activity measurement}

For the NADPH oxidase activity measurement, $5 \times 10^{6}$ neutrophils were isolated, suspended in NBT solution $(4 \mathrm{mg} / \mathrm{ml})$ and incubated for $20 \mathrm{~min}$ in a thermostat-controlled water bath at $37^{\circ} \mathrm{C}$. Then, $1 \mathrm{M}$ $\mathrm{HCl}$ was added to terminate the reaction. After centrifugation $\left(2500 \mathrm{rpm}, 5 \mathrm{~min}, 18-22^{\circ} \mathrm{C}\right), 400 \mu \mathrm{l} \mathrm{DMSO}$ was added to form stable triphenyl-methyl ester. The optical density (OD) was measured at $560 \mathrm{~nm}$ using a spectrophotometer; the greater the OD, the higher the NADPH oxidase activity was determined to be.

\section{Detection of neutrophil apoptosis using Flow cytometry with Annexin V/PI double-staining}

Prepared neutrophil suspensions $\left(1 \times 10^{6}\right.$ cells $/ \mathrm{mL}$ ) were collected in $10 \mathrm{ml}$ centrifuge tubes and were washed according to the kit's instructions. Fluorescent dyes were added, and samples were incubated in the dark at $4^{\circ} \mathrm{C}$ for $20 \mathrm{~min}$. In all, 10,000 cells were detected using flow cytometry with the excitation wave at $488 \mathrm{~nm}$. A pass-band filter with a wavelength of $515 \mathrm{~nm}$ was used to detect FITC fluorescence. An additional filter whose wavelength ex- 
ceeded $560 \mathrm{~nm}$ was used for PI measurement as shown in Figure 5C

\section{SCEG for lymphocytic DNA}

Lymphocytic suspensions were washed with PBS, and the concentration was adjusted to $1 \times 10^{5}$ cells $/ \mathrm{ml}$. The alky comet assay described by Singh et al. was performed according to the kit's instructions. Briefly, the assay involved seven procedures: sheeting, splitting, rinsing, untwisting, electrophoresis, rinsing and staining. The results were observed under ultraviolet light using a fluorescence microscope. Each experiment was replicated twice, and 100 cells were sampled from each group to survey the number of comet cells. The tail distance and length were determined using CASP (casp-1.2.2) software.

\section{Immunofluorescence staining and confocal mi- croscopy}

Cell samples were prepared as previously described Liu.et al (2008) [9]. Briefly, PMN cells were cultured onto four-chamber slides precoated with $1 \%$ gelatin until nearly confluent and fixed with $1 \%$ formaldehyde in PBS at room temperature for $30 \mathrm{~min}$. Cells were washed three times with PBS and permeabilized in $0.1 \%$ TritonX-100 in PBS for 10 min. Slides were blocked with $20 \%$ fetal calf serum in PBS for 30 min at room temperature. Cells were washed with $0.1 \%$ bovine serum albumin/PBS three times with gentle shaking and were incubated at $37^{\circ} \mathrm{C}$ for $2 \mathrm{~h}$ with anti-gp91phox rabbit polyclonal antibody (H-60, Santa Cruz Biotechnology) and anti-p47phox goat polyclonal antibody (C-20, Santa Cruz Biotechnology) at a 1:500 dilution in PBS containing 10\% bovine serum albumin (BSA) and 0.1\% Tween 20. Cells were stained with fluorescein isothiocyanate (FITC)-conjugated rabbit anti-goat IgG (81-1611, Zymed) or Cy5-conjugated goat anti-rabbit IgG (81-6116, Zymed) at a ratio of 1:100 in PBS containing 10\% BSA and 0.1\% Tween 20 at $37^{\circ} \mathrm{C}$ for $1 \mathrm{~h}$. Following extensive washing in PBS, the cells were mounted on slides using a DAPI mounting medium. The stained cells were observed under a confocal laser-scanning microscope (LSM 510 META, Zeiss)

\section{Statistical method}

All measured data were expressed as mean \pm standard deviation and analyzed using SPSS for Windows 15.0. Single factor analysis of variance (ANOVA) was performed. $\mathrm{P}<0.05$ was consider as the level for statistical significance; CASP (casp-1.2.2) software was used for DNA damage analysis. Pearson correlation and stepwise regression analysis was used to measure the correlation between activity of NADPH oxidase, DNA damage, MDA/MPO levels in plasma, and production of ROS.

\section{Results}

\section{Cytokine levels in blood after overtraining}

Blood was sampled $36 \mathrm{~h}$ post-exercise, plasma was separated, and the concentrations of cytokines were measured using ELISA kits. As show in Fig 1, compared with the control group $C$., the concentration of IL- $1 \beta$, IL- 8, TNF- $\alpha$, MCP- 1 and CINC in rat plasma $36 \mathrm{~h}$ after the last training was all highly significantly increased in group E. group D had significantly lower levels of IL-1 $\beta$ and MCP-1, but had notably increased levels of IL- 8 and TNF-a. CINC was decreased, but this was not statistical significant.
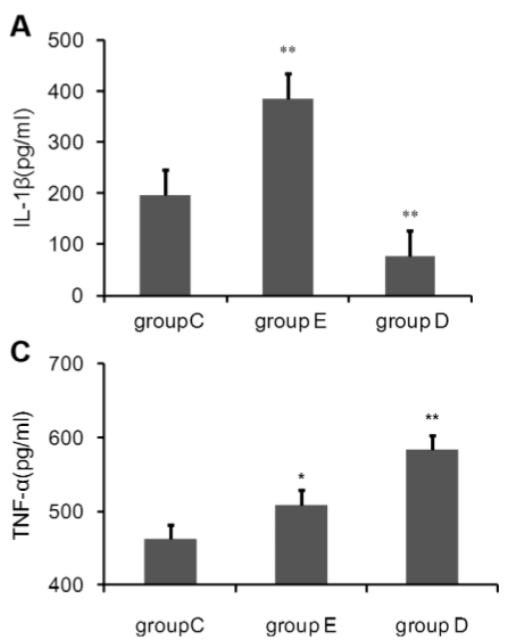
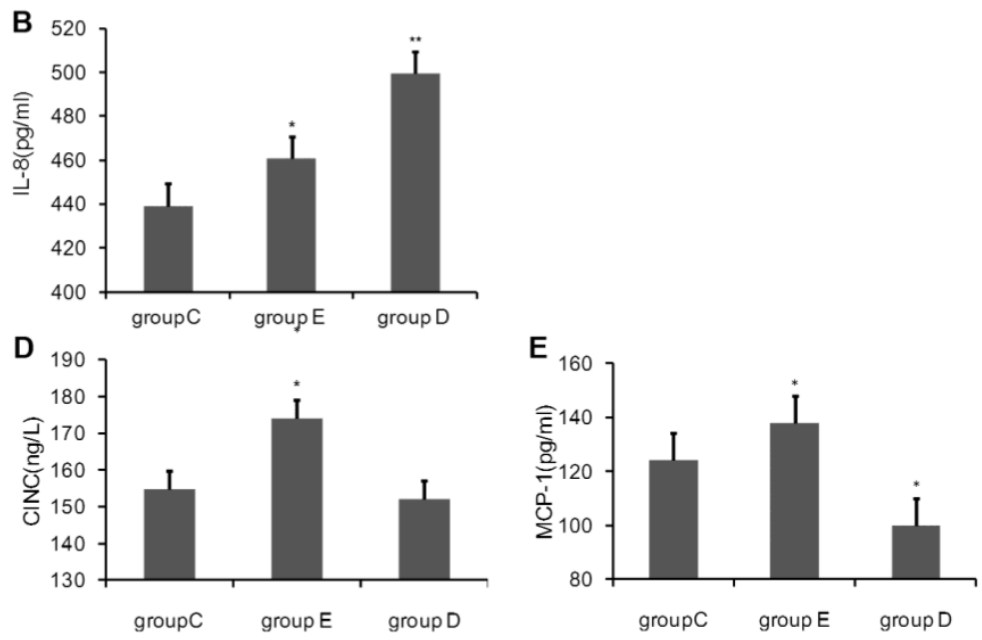

Figure 1. the concentration of Cytokine in rat plasma $36 \mathrm{~h}$ after overtraining. $\mathrm{P}$ values were calculated in comparison with group $C,{ }^{*} \mathrm{p}<0.05 ;{ }^{*} \mathrm{p}<0.01$ (mean $\pm \mathrm{SD} ; \mathrm{n}=8$ per group). Group $\mathrm{C}$ : negative control, group $\mathrm{E}$ : overtraining group, group D: overtraining + DPI intervention group. 


\section{Peroxidase in rat blood after overtraining}

\section{Detection of MDA in blood plasma after overtraining}

As shown in Figure 2, plasma MDA levels in group E suddenly rose $36 \mathrm{~h}$ post-exercise compared with the control group, and this effect was highly statistically significant $(p<0.01)$. MDA levels in group D $36 \mathrm{~h}$ post-exercise were also increased but did not show statistical significance.

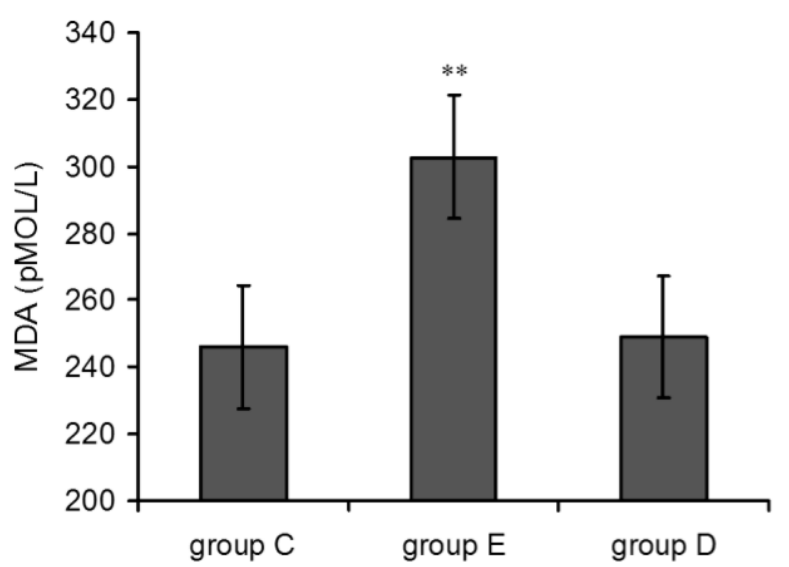

Figure 2. Plasma MDA levels increased $36 \mathrm{~h}$ after exercise. $P$ values were calculated in comparison with group $C,{ }^{*} \mathrm{p}<0.05 ;{ }^{* *} \mathrm{p}<0.01$ (mean $\pm \mathrm{SD} ; \mathrm{n}=8$ per group). Group C: negative control, group E: overtraining group, group D: overtraining + DPI intervention group.

\section{Detection of MPO in plasma after overtraining}

Compared with group $\mathrm{C}$, the concentration of MPO in both group E and group D was increased $36 \mathrm{~h}$ post-exercise. The single factor ANOVA results showed that the increase in group $\mathrm{E}$ was highly statistically significant $(p<0.01)$ but decrease in group $(\mathrm{p}<0.05)$ (Figure 3).

Detection of NADPH oxidase activity in neutrophils after overtraining

A chemiluminescence assay was performed to measure NADPH oxidase activity in neutrophils. The OD values given in Figure 4 indicate that compared with group C, NADPH oxidase activity was significantly higher in group $\mathrm{E}(\mathrm{p}<0.01)$ and in group $\mathrm{D}$ $(p<0.05)$ relative to group $C$.

\section{Detection of apoptotic leukocytes after overtraining}

As shown in Figure 5A and 5B, flow cytometry indicated that the apoptosis and mortality rates for neutrophils from rats in group D and group $\mathrm{E}$ were higher than for those in group C. ANOVA showed that the difference in group $\mathrm{E}$ reached the level of high statistical significance, and the change in group D was statistically significant. In addition, lymphocyte apoptosis followed the same trend seen in neutrophils after overtraining.

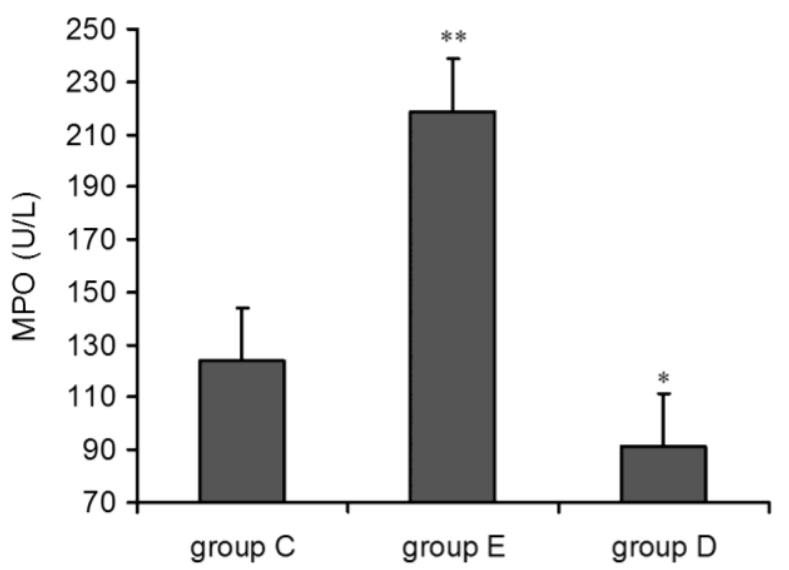

Figure 3. plasma MPO levels increased $36 \mathrm{~h}$ after exercise. $P$ alues were calculated in comparison with group $C$, " $p<0.05 ;{ }^{* *} p<0.01$ (mean $\pm \mathrm{SD} ; \mathrm{n}=8$ per group). Group C: negative control, group E: overtraining group, group D: overtraining + DPI intervention group.

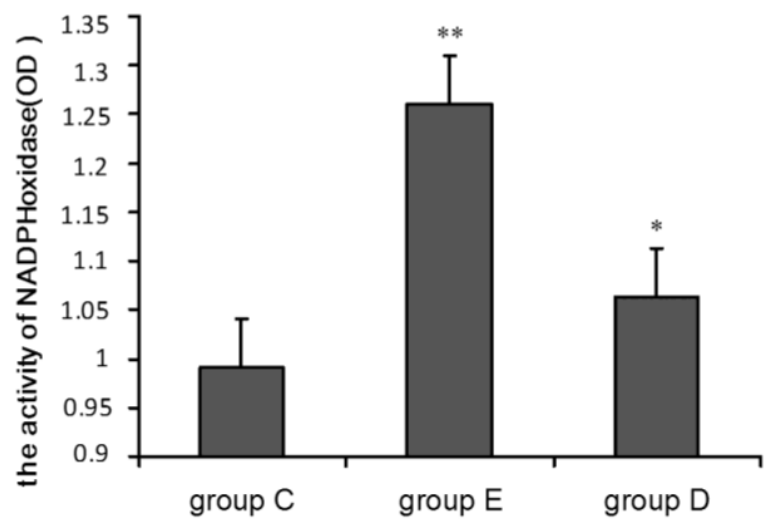

Figure 4. NADPH oxidase activity increased $36 \mathrm{~h}$ after exercise. $P$ values were calculated in comparison with group $C,{ }^{*} p<0.05 ;{ }^{* *} p<0.01$ (mean $\pm S D ; n=8$ per group). Group C: negative control, group E: overtraining group, group D: overtraining + DPI intervention group.

\section{SCGE assay for lymphocyte DNA damage after overtraining}

Figure 6 shows the results of the SCGE assay performed on lymphocytes $36 \mathrm{~h}$ post-exercise to detect cellular DNA damage. Structures shaped like "comet tails" can be observed following SCGE. The extent of DNA migration during electrophoresis, as indicated by the length of the comet tail, directly reflects the degree of DNA damage. Representative fluorescence images are shown in Figure 6. 

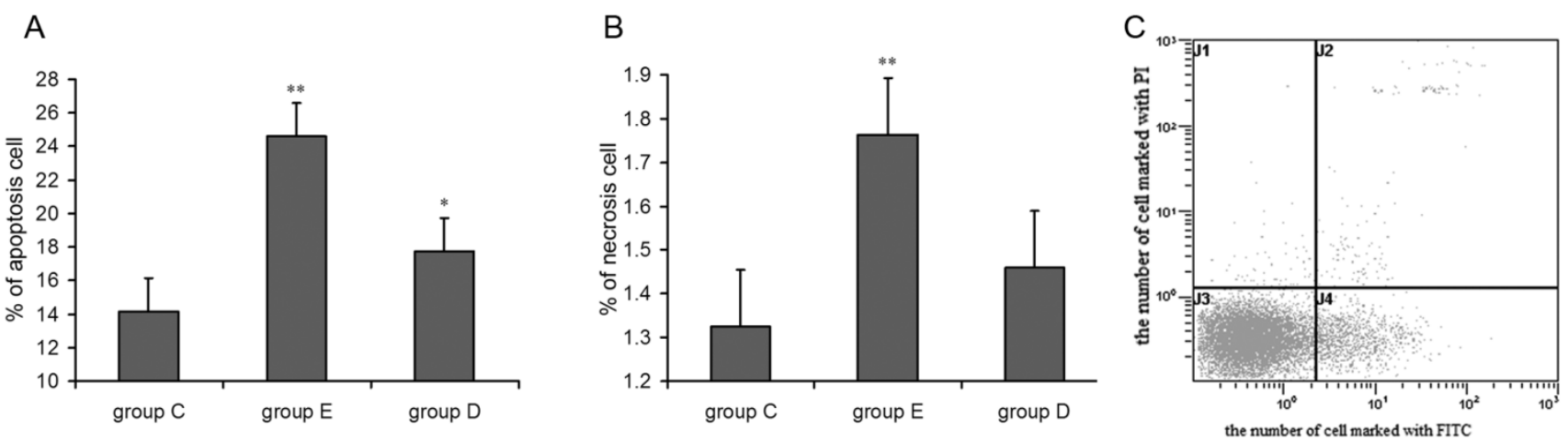

Figure 5. the apoptosis $(A)$ and necrosis $(B)$ rates for neutrophils increased $36 \mathrm{~h}$ after exercise and Flow cytometry image $(C)$. P values were calculated in comparison with group $C,{ }^{*} p<0.05 ;{ }^{* *} p<0.01$ (mean $\pm S D ; n=8$ per group) Group C: negative control, group E: overtraining group, group D: overtraining + DPI intervention group. Figure $5 \mathrm{C}$ means the spots in the left inferior quadrant represent living cells (FITC-/PI-), the right superior quadrant represents non-living cells (FITC+/PI+), and the right inferior quadrant contains apoptotic cells (FITC+/PI-).
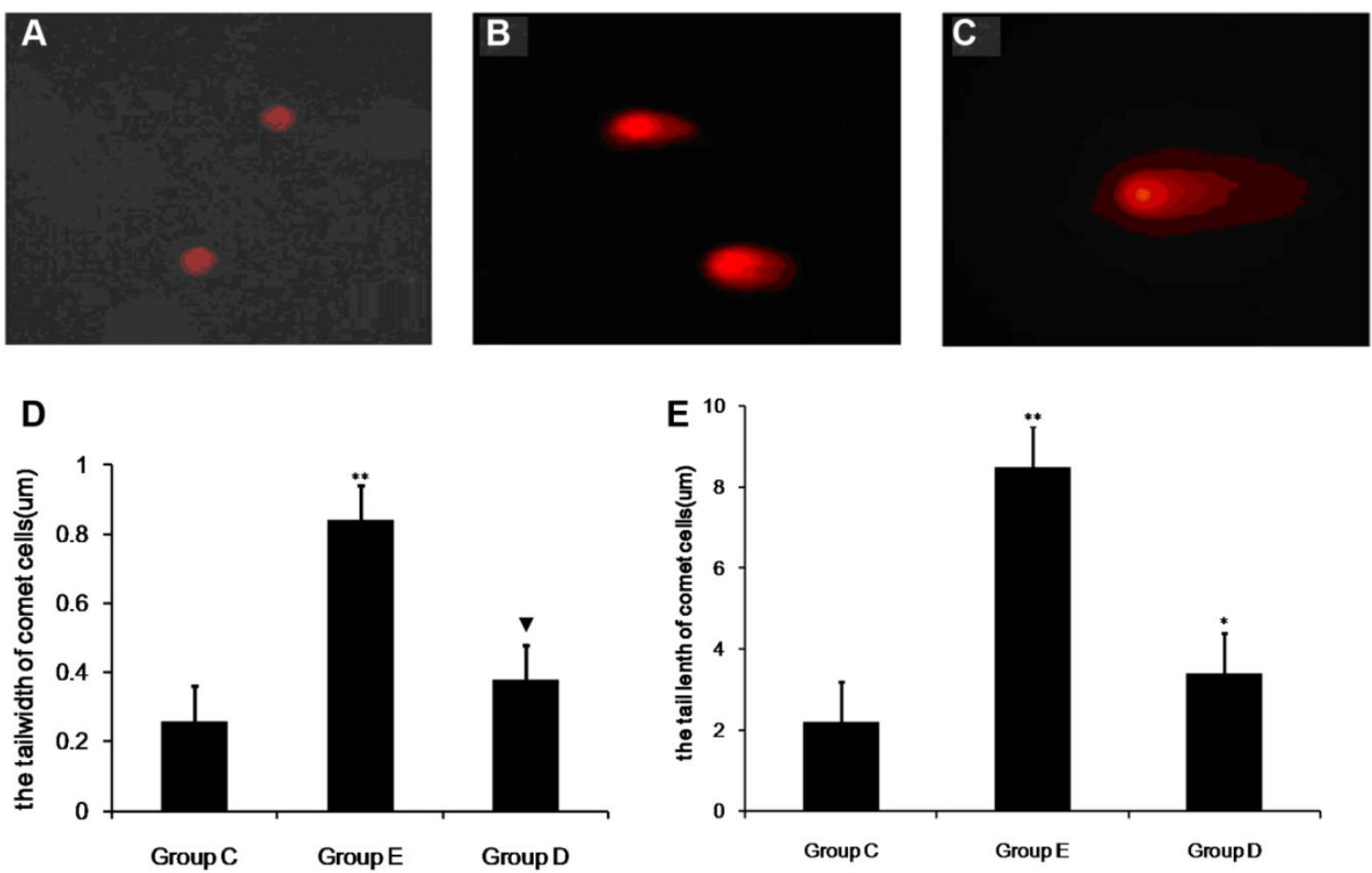

Figure 6. The level of DNA damage in lymphocytes after overtraining. SCGE results showing DNA damage in lymph cells $(\times 200)$. A shows no DNA damage, $B$ shows moderate DNA damage, and $C$ shows serious DNA damage. $P$ values were calculated in comparison with the results for group $C\left({ }^{*} p<0.05 ;{ }^{* *} p<0.01\right)$ and in comparison with the results for group $\mathrm{E}(\boldsymbol{\nabla} \mathrm{p}<0.05$, mean $\pm \mathrm{SD} ; \mathrm{n}=8$ per group $)$. Group $\mathrm{C}$ : negative control, group $\mathrm{E}$ : overtraining group, and group D: overtraining + DPI intervention group.

In all, 100 cells were sampled from each sample to study the percentage of comet cells, and the length and width of comet cell tails were analyzed.The mean percentages of comet cells in the control group, group $\mathrm{E}$ and group $\mathrm{D}$ were $8.33 \%, 12.15 \%$ and $21.52 \%$, re- spectively. As show in Fig 6 compared with group C, the number of comet cells in group $\mathrm{E}$ was significantly higher $(\mathrm{p}<0.01)$. In addition, the width and tail length of comet cells markedly exceeded those of group $C$ $(p<0.05)$. The measurements from group D showed an 
increase, but this was not significant when compared with group $\mathrm{C}$. However, the mean percentages of comet cells, the width and tail length of comet cells from group D were lower than those of group E ( $p<$ 0.05).

\section{The co-localization between gp91phox and p47phox of the NADPH-oxidase subunit in group E using immunocytochemistry and confocal mi- croscopy induced by overtraining}

To find evidence for activation of PMNs, we used immunofluorescence staining to determine whether overtraining induces activation of NADPH oxidase. Translocation of the cytosolic subunit $\mathrm{p} 47$ phox to the membrane is a key step in NADPH oxidase activation (Johnson et al. 1998[10]). We used anti-gp91phox (red fluorescence) combined with an anti-p47phox (green fluorescence) antibody to detect the translocation of the p47phox subunit. As shown in Fig 7A and 7C, p47phox was distributed evenly between the cytoplasm and the nucleus of cells in group $C$ and in gourp D, and no distinct accumulation was detected on the cell membrane, indicating that the majority of p47phox was localized in the cytoplasm of PMNs while the rats was rested, as shown in Fig 7B. The p47phox translocated to the cell membrane and co-localized with gp91phox, suggesting that NADPH oxidase was activated in PMN cells induced by overtraining.
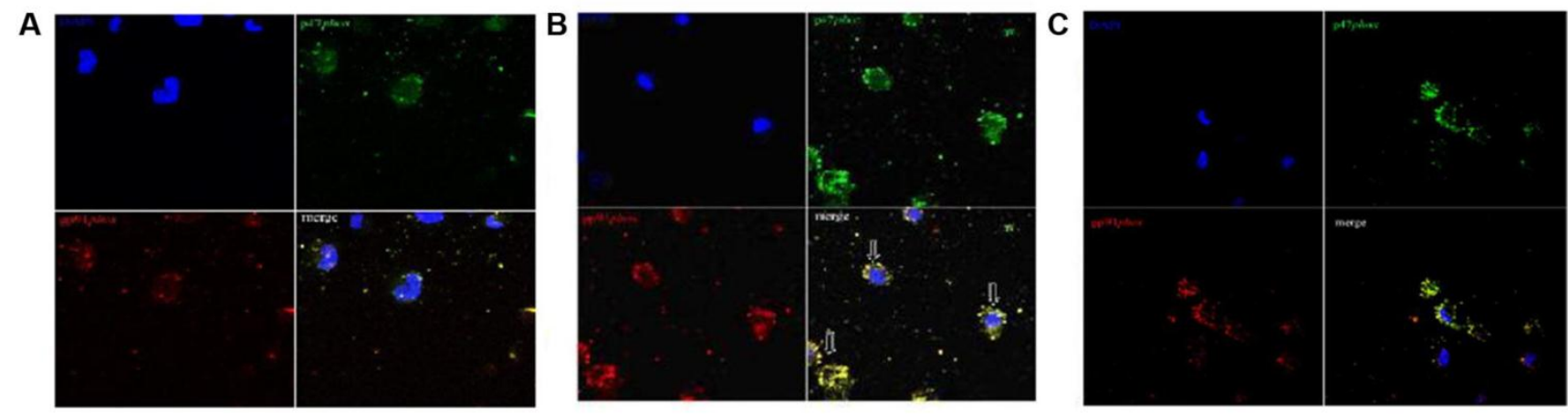

Figure 7. Co-localization between $\mathrm{gp} 91^{\text {phox }}$ and $\mathrm{p} 47^{\text {phox }}$ subunits of NADPH-oxidase in neutrophils after overtraining. A and C: No co-localization between gp9 $1^{\text {phox }}$ and $\mathrm{p} 47^{\text {phox }}$ was observed in control group $\mathrm{C}$ or overtraining + DPI intervention group D in immunocytochemical analysis and confocal microscopy $(\times 200)$. B: The co-localization between gp $91^{\text {phox }}$ and $\mathrm{p} 47^{\text {phox }}$ in overtraining group $\mathrm{E}$ in immunocytochemical analysis and confocal microscopy $(\times 200)$. (arrow indicating cells in merged figures, yellow).

\section{Discussion}

\section{Successful construction of overtraining protocols}

In the present study, the key was to build a successful animal overtraining protocol, which was based on the Hohl(2009,Brazil)overtraining protocol with some modifications. The criteria to evaluate the condition of the rats and judge whether the protocol was successful were as follows: locomotory capacity, physical strength, mental state, weight change, and concentrations of hemoglobin, corticosterone and testosterone. This training protocol had three key features. 1) The load was progressively increased over a long period of time ( 1 week for the acclimatization phase plus 12 weeks training). 2) There were 4 weeks of adaptive training, which allowed all rats to reach a satisfactory adaptive state. 3) The progressive load increase was accomplished by increasing the frequency of training but not increasing the treadmill speed, which lowered the risk of injury and promoted recovery. In this study, there were only two accidental deaths.

\section{The influence of overtraining on cytokine se- cretion in rat}

During the process of immune activation, immune cells are affected by various regulatory factors, such as IL-1 $\beta$, TNF- $\alpha$ and IL-8. IL- $1 \beta$ is an intense pro-inflammatory cytokine. As well as regulating immunological functions mediated by $\mathrm{T}$ cells and $\mathrm{B}$ cells, it acts on leukocytes, macrophages and vascular endothelial cells. TNF- $\alpha$, an important inflammatory mediator produced by activated monocytes and macrophages [11], plays a role in many aspects of innate immunity, including killing and inhibiting tumor cells, promoting phagocytosis of leukocytes, causing fever and inducing acute protein synthesis by hepatocytes, facilitating the differentiation of myeloid cells to macrophages and facilitating cell proliferation and differentiation [12]. TNF- $\alpha$ is also involved in the pathological damage associated with some autoin- 
flammatory diseases [13]. IL-8, which is produced by monocytes and macrophages stimulated with TNF-a, can activate neutrophils to produce two types of responses. One response is to promote the release of cytolysosome and produce a respiratory burst, forming superoxide and hydroxyl peroxide. The other response is to induce phagocytosis of pathogenic microorganisms [14].

The sequence of events that occurs in neutrophil response to microbial invasion includes adherence, chemotaxis, phagocytosis, oxidative burst, degranulation, and microbial killing. Therefore, we selected the cytokine described above as a measure of the response function of neutrophils in different stages of the process of killing germs. The results we measured after overtraining have a concordant rise in rat plas$\mathrm{ma}$, indicating that there is an enormous response to neutrophils that could lead to change of the neutrophil function.

In addition, our previous study [15] and the study by Lancaster (2004) [3] show that overtraining enhances Th2 cell responses and induces a shift from Th1 to Th2 during the differentiation of naïve T helper cells. This implies that the decrease in immune capacity and increase in infection rate post-exercise are mainly related to the suppression of Th1 responses and are less influenced by changes in humoral immunity. This explanation would be consistent with a study showing that exercise could cause an imbalance in immunological regulation resulting in decreased cellular immunity [16].

\section{Activation of NADPH oxidase and MPO by over- training and changes in peripheral blood perox- idation caused by the production of ROS}

NADPH oxidase, a special type of functional enzyme, mediates the production of ROS by phagocytes. The activation of NADPH oxidase catalyzes the reaction $\mathrm{NADPH}+2 \mathrm{O}_{2} \rightarrow \mathrm{NADP}^{+}+\mathrm{H}^{+}+2 \mathrm{O}_{2}^{-}$, with $\mathrm{NADPH}$ as the substrate. $\mathrm{O}_{2}^{-}$forms $\mathrm{H}_{2} \mathrm{O}_{2}$ in a reaction catalyzed by superoxide dismutase (SOD) [17].

NADPH oxidase activation in phagocytes can be induced by a large number of soluble and particulate factors, such as neutrophil adhesion, pro-inflammatory cytokines, lipopolysaccharide, and other agents (El-Benna, et al. 2008) [18]. Exercise, as a kind of excitation, could induce neutrophil activation (Peake,et al.2004) [19]. Although several studies have examined the effects of exercise on the priming and activation of neutrophils (Suzuki, et al. 2003, Peake et al. 2005) $[20,21]$. We detected the removal of $p 47$ phox from the cytoplasm to the membrane and co-localization with the gp91 phox in NADPH oxidase using immunocytochemistry and confocal microsco- py immediately after overtraining. This finding indicates that overtraining activate the neutrophils and induce the consequent response of neutrophils.

MPO is found in azurophil granules in neutrophils and can reduce $\mathrm{H}_{2} \mathrm{O}_{2}$ to hypochloric acid ( $\mathrm{HOCl}$ ) in the presence of chloride, which acts as a potent antioxidant and sterilizing factor. After activation, neutrophils can degranulate and can release MPO into extracellular space, which can cause other tissue damage [22]. Therefore, we selected MPO as a measure for the activity of neutrophils.

After overtraining, NADPH oxidase activity, the concentrations of serum MPO and MDA were determined and compared with that of group $C$ and group D. We found that NADPH oxidase activity was markedly increased and plasma concentrations of MPO and MDA were also increased, Pearson correlation analysis showed a significant relationship between activity of NADPH oxidase and both MPO $(\mathrm{r}=$ $0.78)$ and MDA $(r=0.63)$ levels. This positive correlation supports the hypothesis that overtraining leads to the activation of neutrophils. The activation of $\mathrm{NADPH}$ oxidase releases ROS and $\mathrm{MPO}$, inducing respiratory burst and phagocytosis; consequently, peroxidase levels were increased.

\section{Flow cytometry for the detection of neutrophil and lymphocyte apoptosis after overtraining}

We used FITC-labeled Annexin V and PI double staining to detect apoptosis and necrosis of neutrophols in peripheral blood. The number of necrosis cells measured using this method was used as a marker for the effect of overtraining on neutrophil apoptosis. The results demonstrated that overtraining markedly increases the number of apoptotic and necrosis cells. Compared with group C, the numbers of apoptotic and necrosis cells were lower in group D, suggesting that the production of ROS via the NADPH oxidase pathway in activated leukocytes was probably the main source in peripheral blood. However, the production of ROS during exercise via other pathways cannot be ruled out. Combined with the data showing that the MDA concentration in blood was elevated after overtraining, these results suggest that the overproduction of ROS via the NADPH oxidase pathway was probably the main reason for the elevated level of peroxidation in peripheral blood.

\section{Comet assay for DNA damage}

The comet assay has been developed as a means of detecting cellular DNA damage, and it is generally used in a variety of fields, such as biological monitoring and genetic toxicology [23]. The distance migrated by cellular DNA during electrophoresis di- 
rectly reflects the extent of DNA damage present. Granular cells function mainly in the tissue and spend only a short time in the bloodstream before aging and dying. Lymphocytes, whose lifespans last several months and even as long as a year, mainly reside in the circulatory system, where they proliferate and differentiate. Therefore, we used this method to measure DNA damage in lymphocytes isolated from peripheral blood after overtraining. The DNA damage in lymphocytes in group E was significantly higher than that in group $C$ and in group D was also lower than in group E. The data showed that overtraining lead to the increase of DNA damage and this is related to the production ROS mediated by NADPH oxidase.

\section{Potential mechanism for the effect of ROS re- leased by respiratory burst on lymphocyte DNA damage}

Our study measured DNA damage in lymphocytes after overtraining using the SCGE assay. DPI, an inhibitor of NADPH oxidase, was used as an intervention to determine the role of this pathway in EIS. We found that the degree of DNA damage in the treated group D was lower than that in the group E. Stepwise regression analysis indicated that there is a positive correlation between the activity of NADPH oxidase and both lymphocyte DNA damage $(r=0.67)$ and neutrophil apoptosis $(\mathrm{r}=0.74)$, which implies that the ROS produced by respiratory burst due to overtraining was probably involved in the induction of DNA damage. That is, the release of ROS, mediated by NADPH oxidase during the respiratory burst, not only led to lipid peroxidation in the blood but also caused a series of different perioxidation reactions in other cells. Studies in 2005 by Ogonovszky et al. [24, 25] showed that the levels of 8-oxo-2-deoxyguanosine, a marker of oxidative DNA damage, were increased in the liver after overtraining. In the brain, levels of 8-oxo-2-deoxyguanosine were unchanged, but the activity of the proteasome complex increased in the overtraining group. These findings imply that overtraining induces oxidative damage to nuclear DNA in the liver but does not induce oxidative stress in the brain.

Another studies also reported that free radicals have a damaging effect on DNA [26]. Free radicals can lead to the breakdown of hydrogen bonds in DNA, degradation of bases and the untwisting of the DNA backbone. All nucleic acids can be attacked by free radicals and while this damage can be repaired in some cases, it can also lead to permanent damage. As a result, damage to cellular DNA can change the biological activity of cells and cause gene mutations, tumors and even cell death [27]. Our results showed that the DNA damage in group D was lower than that in the group E, indicating that the NADPH oxidase pathway was probably not the only path leading to production of ROS during exercise

There is evidence that peroxides such as $\mathrm{H}_{2} \mathrm{O}_{2}$ could activate NADPH oxidase [28]. Some research indicated that exercise could change the production of inflammatory and chemotactic factors or production of ROS [29, 30].Therefore, there are three potential pathways leading to DNA damage. 1) The DNA damage caused by ROS could be produced during overtraining via other pathways. 2) Inflammatory factors induced by overtraining could directly damage DNA. 3) The production of ROS, leading to DNA damage, is directly mediated by NADPH oxidase activated during over-exercise. ROS production may also be indirectly related to the activation of NADPH-oxidase through the action of $\mathrm{H}_{2} \mathrm{O}_{2}$ and cytokines. So the true mechanism for the induction of DNA damage in immune cells after overtraining is probably a combination of these three pathways (Figure 8) as above mentioned.

\section{Analysis of the attenuation of cellular immunity caused by overtraining}

Excessive activation of NADPH oxidase in overtraining, positive feedback on NADPH oxidase due to increased production of $\mathrm{H}_{2} \mathrm{O}_{2}$ via other cellular pathways, and the release of inflammatory factors induced by oxidative stress result in increased production of ROS and the disturbance of the ROS equilibrium state [31-33].

In conclusion, the reduction in cellular immunity caused by overtraining is due to a combination of factors. Excess ROS in cells damages DNA, lipids and proteins indirectly and induces apoptosis directly via signaling pathways mediated and activated by ROS [34]. ROS leads to phagocytic cell death by interrupting tyrosine phosphorylation induced by the deactivation of AMPK in macrophages [35]. This process leads to decreased innate immune function by phagocytes. The role of phagocytes in mediating $\mathrm{T}$ cell differentiation by secreting cytokines and chemotactic factors would also be affected. Our previous study also showed an exercise-induced Th1/Th2 lymphocyte imbalance, which may be related to a reduction in NKT immunoregulatory cell numbers [15]. In addition, the overproduction of ROS can damage lymphocyte DNA and change cellular activities, which lead to gene mutations, tumors and lymphocyte death. The decrease in cellular immunity involved the attenuation of both innate immunity, particularly phagocyte responses, and adaptive immunity involving $\mathrm{T}$ cells. 


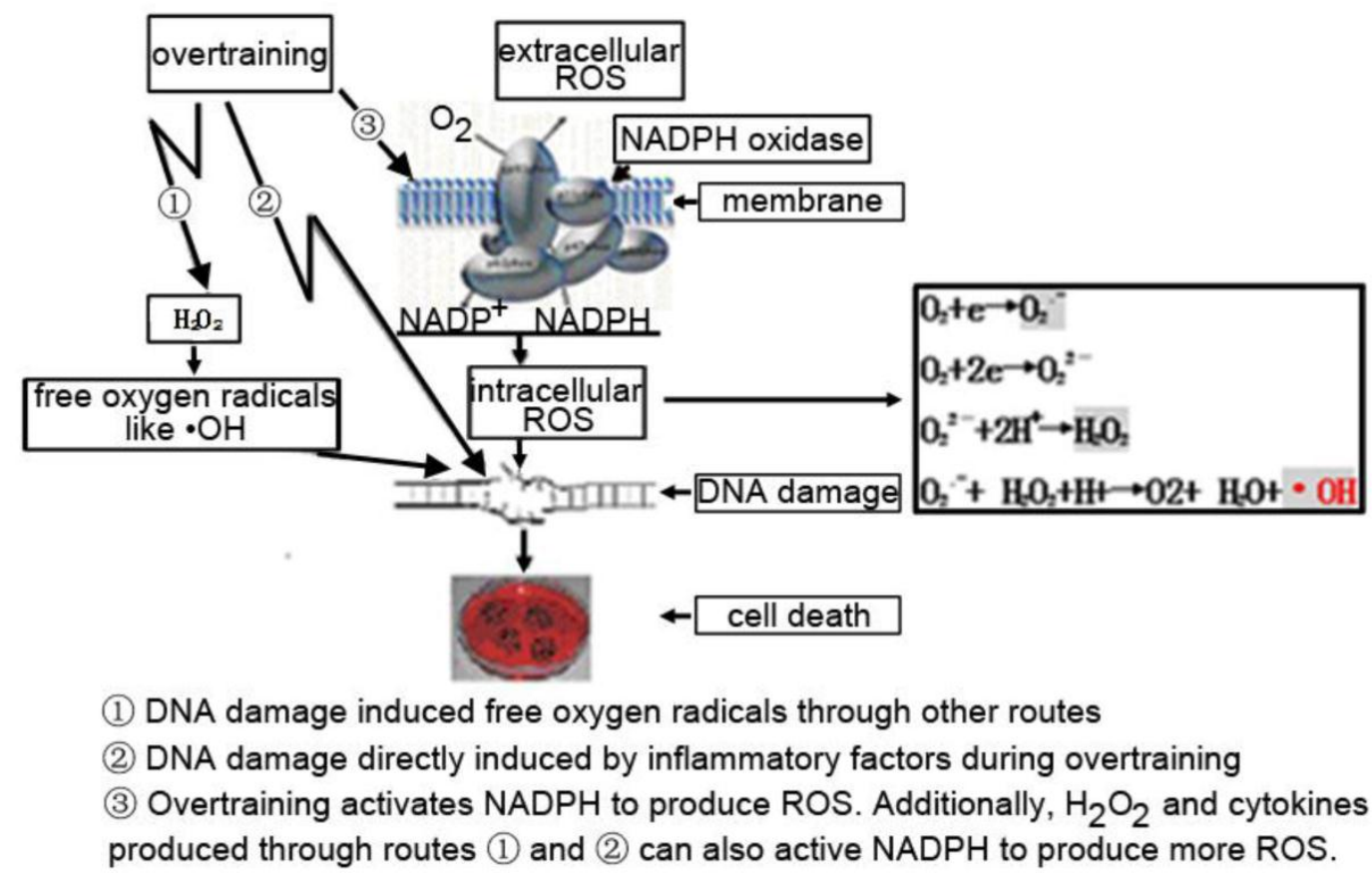

Figure 8. The possible pathway that induced DNA damage caused by overtraining.1) The DNA damage caused by ROS could be produced during overtraining via other pathways. 2) Inflammatory factors induced by overtraining could directly damage DNA. 3) The production of ROS, leading to DNA damage, is directly mediated by NADPH oxidase activated during over-exercise. ROS production may also be indirectly related to the activation of NADPH-oxidase through the action of $\mathrm{H}_{2} \mathrm{O}_{2}$ and cytokines.

\section{Conclusion}

Overtraining increased the secretion of peripheral blood inflammatory factors and cytokines. As a result, overtraining might induced tissue inflammation and affect $\mathrm{T}$ lymphocyte differentiation, leading to dysregulation of the Th1/Th2 balance and the attenuation of cellular immunity.

Excessive production of ROS induced by overtraining could upregulated lipid peroxidation levels in peripheral blood and lead to reduced phagocyte function, lymphocyte injury, a bulk release of inflammatory factors and changes to immunological regulatory factors, which all contribute to cellular immune and the exercise-induced immunosuppression.

Overtraining could activate NADPH oxidase and cause increased production of ROS in neutrophils. The overactive NADPH oxidase leads to the superoxide anion production induced by overtraining. More importantly, our pilot study suggests that the excessive oxidative stress generated by NADPH oxidase is responsible for the neutrophil apoptosis and lymphocyte DNA damage seen in overtraining. These observations, although preliminary, may be of critical value to the modification of oxidative stress induced by overtraining and the prevention of exercise-induced immunosuppression.

\section{Acknowledgments}

We thank Jonathan Peake for the guidance in the study. This work was supported by the grants from National Natural Science Foundation (30971422) and Shanghai Key Discipline Construction Program (S30802).

\section{Conflict of Interests}

The authors have declared that no conflict of interest exists.

\section{References}

1. Nieman DC, Berk M, Simpson-Westerberg K. Effects of long-endurance running on immune system parameters and lymphocyte function inexperienced marathoners. Int J Sports Med.1989; 10: 317-23.

2. Pedersen BK, Ullum H. NK cell response to physical activity: possible mechanisms of action. Med Sci Sports Exerc.1994; 26: 140-6.

3. Lancaster GI, Halson SL, Khan Q, et al. Effects of acute exhaustive exercise and chronic exercise training on type 1 and type 2 T lymphocytes. Exerc Immunol Rev. 2004; 10: 91-106.

4. Nathan C. Neutrophils and immunity: challenges and opportunities. Nat Rev Immunol.2006; 6:173-82.

5. Singh NP, McCoy MT, Tice RR, et al. A simple technique for quantitation of low levels of DNA damage in individual cells. Exp Cell Res. 1988;175:184-91. 
6. Siragy HM, Huang J. Renal (pro)renin receptor upregulation in diabetic rats through enhanced angiotensin AT1 receptor and NADPH oxidase activity. Exp Physiol.2008; 93:709-14.

7. Hohl R, Ferraresso RL, De Oliveira RB, et al. Development and characterization of an overtraining animal model. Med Sci Sports Exerc.2009; 41: 1155-63.

8. Wang R. Chen PJ. Modulation of Dendritic Cells and NKT Cells by Excessive Exercise in Rats. Journal of Medical and Biological Engineering.2009; 29(4): 190-4.

9. Liu Q, He X, Liu Y, Du B, Wang X, Zhang W et al. NADPH oxidase-mediated generation of reactive oxygen species: A new mechanism for X-ray-induced HeLa cell death. Biochem Biophys Res Commun. 2008;377:775-9.

10. Johnson JL, Park JW, Benna JE, Faust LP, Inanami O, Babior BM. Activation of p47phox, a cytosolic subunit of the leukocyte NADPH oxidase. Phosphorylation of ser-359 or ser-370 precedes phosphorylation at other sites and is required for activity. J Biol Chem. 1998;273:35147-52.

11. Kilpatrick LE, Sun S, Li H, et al. Regulation of TNF-induced oxygen radical production in human neutrophils: role of delta-PKC. J Leukoc Biol. 2009; 87:153-64.

12. Lin WW, Karin M. A cytokine-mediated link between innate immunity, inflammation, and cancer. J Clin Invest.2007;117:1175-83.

13. Michael JM, Kim YS, gangL Z. TNF [alpha] and reactive oxygen species in necrotic cell death. Cell Res. 2008; 18: 343-9.

14. Kato T, Kitagawa S. Regulation of neutrophil functions by proinflammatory cytokines. Int J Hematol. 2006; 84: 205-9.

15. Wang R Chen PJ. Modulation of NKT cells and Th1/Th2 imbalance after a-GalCer treatment in progressive load-trained rats. Int J Biol Sci. 2009; 5: 338-43.

16. Gomez MD. Effects During Intense Training on Cellular Immunity, Hormones and Respiratory Infections. Encyclopedia Neurosci.2009; 19: 3856-60.

17. Nauseef WM. Biological roles for the NOX family NADPH oxidases. J Biol Chem. 2008; 283:16961-5.

18. El-Benna J, Dang PM, Gougerot-Pocidalo MA. Priming of the neutrophil NADPH oxidase activation: role of p47phox phosphorylation and NOX2 mobilization to the plasma membrane. Semin Immunopathol. 2008; 30:279-89.

19. Peake JM, Suzuki K. Neutrophil activation, antioxidant supplements and exercise-induced oxidative stress. Exerc Immunol Rev. 2004;10:129-41.

20. Suzuki K, Nakaji S, Yamada M, Liu Q, Kurakake S, Okamura N et al. Impact of a competitive marathon race on systemic cytokine and neutrophil responses. Med Sci Sports Exerc. 2003;35:348-55.

21. Peake JM, Suzuki K, Wilson G, Hordern M, Nosaka K, Mackinnon $\mathrm{L}$ et al. Exercise-induced muscle damage, plasma cytokines, and markers of neutrophil activation. Med Sci Sports Exerc. 2005; 37:737-45.

22. Zhang $\mathrm{R}$, Brennan $\mathrm{ML}, \mathrm{Fu} \mathrm{X}$, et al. Association between myeloperoxidase levels and risk of coronary artery disease. JAMA.2001; 286:2136-42.

23. McKelvey-Martin VJ, Green MH, Schmezer P, et al. The single cell gel electrophoresis assay (comet assay): a European review. Mutat Res.1993; 288: 47-63.

24. Ogonovszky H, Sasvári M, Dosek A, et al. The effects of moderate, strenuous, and overtraining on oxidative stress markers and DNA repair in rat liver. J Appl Physiol. 2005; 30(2):186-95.

25. Ogonovszky H, Berkes I, Kumagai S, et al. The effects of moderate-, strenuous- and over-training on oxidative stress markers, DNA repair, and memory, in rat brain. Neurochem Int. 2005; 46: 635-40.

26. Box HC, Budzinski EE, Dawidzik JB, et al. Free radical-induced tandem base damage in DNA oligomers. Free Radic Biol Med.1997; 23: 1021-30.
27. Sonntag C. Free-radical-induced DNA damage and its repair: a chemical perspective. Berlin Heidelberg: Springer-Verlag. 2006: 328-34.

28. Veal EA, Day AM, Morgan BA. Hydrogen peroxide sensing and signaling. Mol Cell.2007; 26:1-14.

29. Nielsen HG, Hagberg IA, Lyberg T. Marathon running leads to partial exhaustion of ROS-generating capacity in leukocytes. Med Sci Sports Exerc.2004; 36: 68-73.

30. Peake JM, Suzuki K, Hordern M, et al. Plasma cytokine changes in relation to exercise intensity and muscle damage. Eur J Appl Physiol.2005; 95: 514-21.

31. Arbiser JL, Petros J, Klafter R, et al. Reactive oxygen generated by Nox1 triggers the angiogenic switch. Proc Natl Acad Sci U S A. 2002; 99: 715-20.

32. Bluml S, Rosc B, Lorincz A, et al. The oxidation state of phospholipids controls the oxidative burst in neutrophil granulocytes. J Immunol.2008; 181: 4347-53.

33. Droge W. Free radicals in the physiological control of cell function. Physiol Rev. 2002; 82: 47-95.

34. Kamata H, Honda S, Maeda S, et al. Reactive oxygen species promote TNFalpha-induced death and sustained JNK activation by inhibiting MAP kinase phosphatases. Cell.2005; 120: 649-61.

35. Alba G, El Bekay R, Alvarez-Maqueda M, et al. Stimulators of AMP-activated protein kinase inhibit the respiratory burst in human neutrophils. FEBS Lett.2004;573: 219-25. 